\title{
Macroscopic simulation of atom-sized structures of functional materials: phenomenology of the elongated electrode system
}

\author{
A.P.Pospelov ${ }^{1}$, G.V.Kamarchuk ${ }^{2}$, A.V.Savytskyi ${ }^{2}$,

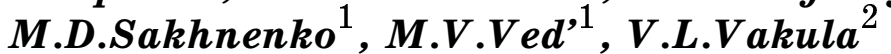 \\ ${ }^{1}$ National Technical University "Kharkiv Polytechnic Institute", \\ 21 Kyrpychov Str., 61002 Kharkiv, Ukraine \\ ${ }^{2}$ B.Verkin Institute for Low Temperature Physics and Engineering, \\ National Academy of Sciences of Ukraine, \\ 47 Nauky Ave., 61103 Kharkiv, Ukraine
}

Received April 6, 2017

\begin{abstract}
A new phenomenological approach is proposed to formalize "the elongated element" as electrochemical medium in which electrode reactions are localized on the surface of an elongated first-class conductor with the outline dimensions ratio $\left(d / l_{e l}\right) \rightarrow 0$, where $d$ is the effective cross section size and $l_{e l}$ is the length of the conductor in contact with a second-class conductor. This architecture of electrochemical system is used to develop ultrasensitive broadly functional sensor devices. The object under consideration can become the basis for creation of state-of-the-art, yet inexpensive, technologies for synthesizing functional atomsized structures and nanostructured materials.

Keywords: atom-sized structures, electrochemical system, elongated element, sensor devices.

Предложен феноменологический подход к формализации "протяженного элемента" как электрохимической системы, в которой электродные реакции локализованы на поверхности протяженного проводника первого рода с соотношением габаритных размеров $\left(d / l_{e l}\right) \rightarrow 0$, где $d$ - әффективный размер поперечного сечения, $l_{e l}$ - длина проводника в контакте с проводником второго рода. Такая архитектура электрохимической системы использована для разработки сверхчувствительных сенсорных устройств с широкими функциональными возможностями. Рассмотренный объект может стать основой для создания передовых, в то же время недорогих технологий синтеза функциональных атомно-размерных структур и наноструктурных материалов.
\end{abstract}

Макроскопічне моделювання атомно-розмірних структур функціональних матеріалів: феноменологія протяжної електродної системи. О.П.Поспєлов, Г.В.Каларчук, А.В.Савищький, М.Д.Сахненко, М.В.Вєдь, В.Л.Вакула.

Запропоновано феноменологічний підхід до формалізації "протяжного елемента" як електрохімічної системи, в якій електродні реакції локалізовані на поверхні протяжного провідника першого роду із співвідношенням габаритних розмірів $\left(d / l_{e l}\right) \rightarrow 0$, де $d-$ ефективний розмір поперечного перерізу, $l_{e l}$ - довжина провідника у контакті з провідником другого роду. Таку архітектуру електрохімічної системи використано для розробки надчутливих сенсорних пристроїв з широкими функціональними можливостями. Розглянутий об'єкт може стати основою для створення передових, в той же час недорогих технологій синтезу функціональних атомно-розмірних структур і наноструктурних матеріалів. 


\section{Introduction}

Creation of new functional nanostructured materials is one of the most topical and promising research areas in modern materials science [1-3]. Traditionally, this kind of studies requires a high-tech synthesis process followed by investigation of the obtained products. This results in the high cost of developments, which may become an obstacle to their implementation. Development of nanomaterials and nanostructures based on technological principles which are free of these drawbacks is thus quite promising. This approach can successfully be realized through employment of fundamental laws of physical chemistry and Yanson point-contact spectroscopy [4]. As has recently been shown [4,5], a Yanson point contact in the model of long channel allows one to realize and demonstrate unique fundamental properties of the new type of nanostructured electrochemical electrode system. The system was given the name of electrochemical elongated element [6]. This object can become a basis for development of advanced, yet not expensive, technologies of synthesis of functional atom-sized structures and nanostructured materials [4,7], hence the importance of learning the nature and main physico-chemical properties of the electrochemical elongated element.

Presently, the theory of elongated element is still evolving. At this stage, a phenomenological description of the object is needed to create a logically interrelated system of concepts and statements about its properties and develop an internally coherent thesaurus. The aim of the present paper is to phenomenologically consider one of the aspects of the elongated electrode system (EES), viz. the distance between the electrodes formed on the surface of this object when an electric field is applied.

In the classical case, electrochemical cells contain at least two electrodes made of solid electroconductive material with its surface in contact with electrolyte. Modernization of the electrochemical cells with the purpose of meeting the present-day technological requirements was aimed mainly at solving the problem of energy consumption reduction and reaching new levels of miniaturization and functionality. This was largely achieved by reducing the distance between the electrodes. In applied electrochemistry, the lower limit of the reduction was determined by technological factors (impeded electrolyte circulation, growing probability of direct electric conductivity with growing den- drites, surface blocked by gas bubbles, etc.), but in fundamental research there were no such restrictions. A new approach to studying thermodynamic and kinetic laws of electrochemical processes was realized on the basis of the so called thin layer cells [8]. The principal element of these cells is a pair of flat electrodes with a few-micron-wide gap in between. In the last decades, the rapid development of nanotechnologies made it possible to reduce the distance between the electrodes to a few hundreds of nanometers. In these electrochemical cells, the diffusion and diffuse layers of the counter electrodes overlap, which causes hard-to-explain size effects and substantial deviations from the classical thermodynamic laws [9]. The cells are produced with the help of expensive ultrahigh-precision instruments which require specially trained operating personnel. Further decrease in the interelectrode distance will require even more complex equipment and highly specialized maintenance staff.

Are there any technical tools left in reserve and can they be used to push the existing limits? To answer the question one needs to go beyond the linear logical premises which imply reducing the distance between the electrodes. An alternative approach is to fundamentally change the architecture of the electrode system to form an elongated element [6]. Since the current distribution in the electrochemical elongated element [10] is indicative of electrochemical conjugative processes taking place along its surface, it is possible to give a more detailed definition of the structure elongated electrochemical system. EES is viewed as an electrochemical system in which electrode reactions are localized on the surface of an elongated first-class conductor with its outline dimensions ratio $\left(d / l_{e l}\right) \rightarrow 0$, where $d$ is an effective cross section size (diameter) and $l_{e l}$ ("elongated") is the length of the conductor in contact with the second-class conductor. The interelectrode distance is understood to be the shortest distance between the areas of the conductor surface affected by electrochemical conjugative reactions. This interpretation allows the interectrode distance to be formed not only by mechanically pulling apart the counter electrodes until the necessary distance is achieved, but also by choosing the appropriate materials for the system and the regime of electrolysis. 


\section{Experimental}

Experiments were carried out at room temperature in a special electrochemical cell in the form of a cylindrical container made of glass. A straight metallic conductor was placed in the cell. The geometry of the experiment was to reproduce a macroscopic model of a nanostructured elongated element [4]. An EES was created by immersing a silver wire with a diameter of $0.2 \mathrm{~mm}$ into a 0.1-mole aqueous solution of analytically pure $\mathrm{AgNO}_{3}$. Bidistilled water was used as the solvent. The length of the wire section immersed into the electrolyte $\left(l_{e l}\right)$ was $260 \mathrm{~mm}$. To polarize the EES, a stabilized power source GW INSTEK GPS-2303 was used, the current in the polarization circuit was controlled with a KEITHLEY2000 multimeter. In order to electrically separate the power circuit and the metering circuit, an autonomous $220-\mathrm{V}$ ac power supply was organized from a dc-to-ac converter connected to a $12-\mathrm{V}$ rechargeable battery.

The metering circuit included a KEITHLEY-2000 multimeter operating in the regime of high-resistance voltmeter, a silver chloride reference electrode ESr-10103 immersed into a saturated aqueous solution of $\mathrm{KCl}$, a pressure probe with a conducting silver contact, a buffer container with a 0.1 mole aqueous solution of $\mathrm{KNO}_{3}$, and two electrolytic bridges made as U-shaped glass tubes, one of which filled with $\mathrm{KCl}$ solution and the other containing $\mathrm{KNO}_{3}$ solution. The solutions in the tubes were thickened with agar-agar.

Experimental studies included scanning (recording) electrode potential along a conductor length $x$ in the range $x=\left\{0-l_{e l}\right\}$ with a measurement pitch $\Delta x$ upon its polarization by currents of various magnitude (I), obtaining an array of $E(I, x)$ values, and comparing them with calculated de- pendences. The arrangement of the setup was standard; the measurement procedure consisted of traditional operations [11].

\section{Results and discussion}

In the simplest case, an elongated element is realized when a current $I$ flows through a first-class conductor with its surface in contact with a second-class conductor. Since electrochemical processes take place on the surface of a conductor of finite cross-section, let us introduce the concept of voltage median boundary (VMB). VMB is a locus of points on the conductor surface which forms a plane perpendicular to the main axis and divides the conductor into two sections characterized by equal potential drops. It is obvious that if the cross-section of the first-class conductor $\mathrm{AD}$ is constant, the VMB belongs to the plane which passes through its geometrical centre $F$ (Fig. 1). To adapt the considered model for real conditions [4], let us use a truncated cone as an approximative figure (Fig. 1, dashed line). This reflects the fact that redox processes which involve first-class metallic electrodes result in accumulation of solid metal in the cathode section and its dissolution in the anode section. The potential distribution along the main axis of the conductor is monotonous. Let $x_{r}$ be a normalized coordinate (in portions of $l_{e l}$ ) on the longitudinal axis of conductor of length $l_{e l}$, i.e. $x_{r}=x / l_{e l}$. Let us assume that the cone base has a diameter $d_{1}$ and crosses the coordinate axis, which coincides with the truncated cone axis, at $x=0$, while its top with a diameter $d_{2}$ crosses it at $x=l_{e l}$. With an electric field applied, the processes of metal deposition and dissolution occurring at the conductor surface will change the cone dimensions: the base diameter $d_{1}$ will grow, while the diameter of the cone top $d_{2}$ will tend to zero (until the direct electronic conduction ceases at the wa-

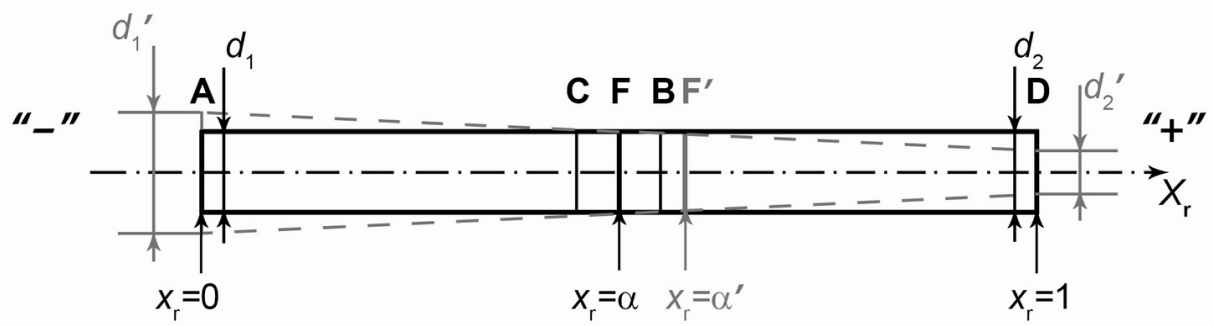

Fig. 1. A schematic view of an elongated element. Original state: $d_{1}=d_{2}, x_{r}=\alpha ; F$ is the coordinate of the polarization inversion boundary (PIB). State after exposure to electric field: $d_{1}^{\prime}>d_{2}^{\prime}, x_{r}=\alpha^{\prime} ; F^{\prime}$ is the PIB coordinate. AC is the section of cathode polarization of the surface; BD is the section of anode polarization of the surface. $d_{1}$ is the diameter of the base connected to the negative pole of the source, $d_{2}$ is the diameter of the top connected to the positive pole of the source. 
terline) and the VMB will thus approach the D point.

In the general case, some voltage must be applied to the EES ends to get the electrode processes started. This voltage can be called electrode system decomposition voltage $\left(U_{d e c}\right)$. It has its own value for every system. The value corresponds to the difference of the lowest (in absolute values) potentials on the EES surface at which conjugative electrode reactions start. The decomposition voltage of an electrode system is determined by its nature. Initially, this voltage is realized over the whole conductor length (section AD). As current $I$ grows, there appear on the conductor surface areas with cathode (AC) and anode (BD) processes taking place. Section CB thus becomes a measure of $U_{d e c}$, being exactly the interelectrode distance in a planar configuration. Further current growth shortens the CB section. But for any infinitely large current the distance will remain nonzero because in the discussed case $U_{d e c} \neq 0$. It should be taken into account that the last statement is a formalized one and clearly characterizes the model under consideration. Larger currents will lead, quite naturally, to thermal destruction of the conductor.

Having said that, we can use the following equations for the coordinates of $\mathrm{C}$ and $\mathrm{B}$ :

$$
\begin{gathered}
C=\frac{\left(1-\bar{U}_{d e c}\right) \alpha}{1+\bar{U}_{d e c}(1-2 \alpha)}, \\
B=\frac{\left(1+\bar{U}_{d e c}\right) \alpha}{1-\bar{U}_{d e c}(1-2 \alpha)} .
\end{gathered}
$$

Here $\bar{U}_{d e c}=U_{d e c} / U$ is a reduced value of decomposition voltage $U_{d e c}$ of the electrochemical system, while $\alpha$ is a reduced VMB coordinate defined as

$$
\alpha=(1+\delta)^{-1}
$$

where $\delta=d_{2} / d_{1}$ is the degree of taper.

Thus the zone of electrochemical indifference can be defined as one including the VMB section of the EES surface where the potential drop is $U_{d e c}$. Then the indifference zone length, that is the distance between the spots where the realization of anode and cathode processes starts (section $\mathrm{BC}$ ), is

$$
B-C=\frac{4 \alpha(1-\alpha) \bar{U}_{d e c}}{1-\bar{U}_{d e c}^{2}(1-2 \alpha)^{2}} .
$$

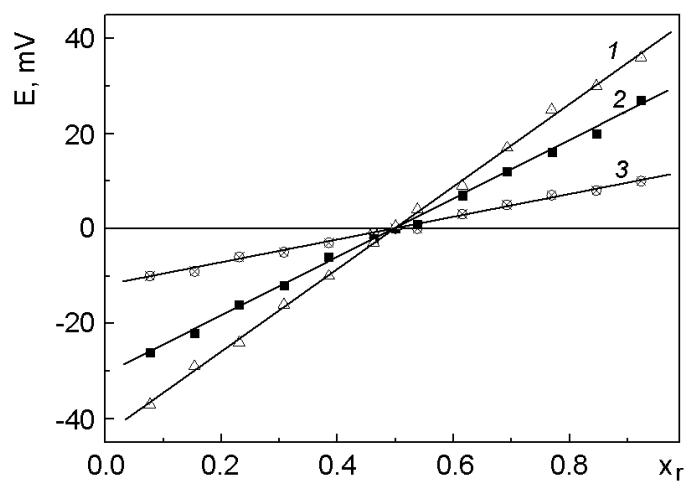

Fig. 2. Distribution of surface polarization of an elongated electrode system $\mathrm{Ag}_{\mathrm{AgNO}}$, $\mathrm{H}_{2} \mathrm{O} \mid \mathrm{Ag}$ along the main axis when the following currents (in A) flow through the conductor: $0.7(1), 0.5(2), 0.2(3) . E$ is the polarization, $x_{r}$ is a reduced coordinate along the longitudinal axis of the conductor.

It thus follows that in the considered case the electrode distance is not related to the steric parameters of the system, being determined by its character and the magnitude of electric field.

Finally, we can create a system with $U_{d e c}$ $=0$, which implies electrochemical destruction for any arbitrary small voltage $U$ applied to the ends of the elongated element, with rates of the electrode processes varying monotonously (as in the previous case) along the main axis (Fig. 2).

The experimentally obtained dependences reported here are in good agreement with the theoretical ones calculated in accordance with Ohm's law with electric parameters of the conductor taken into account (Fig. 2). The high degree of correlation between the measured and calculated data is largely due to the absence of blocking of electrical activity of the polarized surface during the potential measurement. In the classical case, the lines of force of the electric field are on the outer side of the polarized surface and thus any object near the interface causes their distortion which results in experimental errors. In the case of EES, the conductor surface is polarized with no auxiliary electrode used, which eliminates blocking of surface and allows most reliable potential values to be obtained.

Voltage drop over any section of the EES is equal to the difference of the potentials at the opposite ends of the section. VMB with the coordinate $x_{r}=\alpha$ can be chosen as the reference point. Thus the polarization of EES sections decreases monotonously to zero at $x_{r}=\alpha$, where no processes occur. At 
any other $x_{r}$, the polarization is nonzero and anode and cathode electrochemical conjugative decomposition reactions take place. In this case, VMB becomes polarization inversion boundary and section $\mathrm{BC}$ degenerates into a point. Therefore the interelectrode distance becomes equal to zero.

To understand the physical meaning of this statement, one needs to look at the system on the atomic level. From the viewpoint of classical chemistry, the situation with zero interelectrode distance excludes presence and, even more so, any influence of electrolyte, while in a system with an EES electrolyte plays an important role. Actually, if an atom is subject to both anode and cathode polarization, they can be thought of as compensating each other. In this case, the atom is in a pseudoequilibrium state and its behaviour is determined by the exchange current of the respective electrode. The atom settled life time $(\tau)$ can be estimated with the following equation:

$$
\tau=\frac{n F}{2 \pi r^{2} N_{A} j_{0}},
$$

where $n F$ is the charge needed to reduce to metal one mole of metal ions $M^{n+}, r$ is the atomic radius of the metal, $N_{A}$ is the Avogadro constant, and $j_{0}$ is the exchange current density.

For an $\mathrm{Ag} \mid \mathrm{AgNO}_{3}$ electrode $\left(0.1 \mathrm{~mole} / \mathrm{dm}^{3}\right)$, the atom settled life time is $\tau \approx 10^{-2} \mathrm{~s}$, which corresponds to the frequency of $100 \mathrm{~Hz}$. This frequency characterizes the intensity of the renewal of a crystalline lattice singularity node. In practice, PIB includes a cluster of such nodes residing on a plane normal to the conductor axis. It should be kept in mind that in a constant electric field PIB drifts along the main axis of EES. It is due to the fact that electrochemical processes cause redistribution of resistance of cathode- and anode-polarized sections of the conductor and, therefore, displacement of the coordinate of the point in which the potential inversion plane crosses the main axis. This can be seen very clearly in a system consisting of first-class metallic electrodes. In such a system, metal deposits on the surface of the cathode-polarized section of the conductor, while the surface of the anode-polarized section gets dissolved. This results in a PIB drift in the direction of the positive pole of the conductor. Thus a real system displays the so called relay-race singularity, which means that there are no nodes that could be con- sidered as "special". After a long exposure of the system to electric field significant transformations take place with a geometry corresponding to the truncated cone paradigm: the direct electronic conduction is destroyed in the waterline region on the positive pole side and a spike is formed with a radius of curvature of the order of that of an atom. The cathode-polarized section gets thicker thanks to the deposited metal and the cross section diameter reaches its maximum value in the vicinity of the waterline. In the region of PIB localization, the diameter does not change because of the absence of polarization. This process is confirmed by experimental results [4], which allow multiple observation of the formation of monoatomic dendrite Yanson point contacts during the electrochemical cyclic switchover effect discovered by us.

It should be noted that as PIB drifts towards the positive potential values, the singularity nodes enter the region of a higher concentration of metal ions near the solid phase surface because of the finite value of the diffusion transfer rate. In the close proximity of the waterline, this effect becomes particularly pronounced, the more so because the motion is accelerated. Since the exchange current density increases as ion concentration grows in the adjacent electrolyte layer, we can deduce from Eq. (5) that the PIB drift is associated with the increase in the frequency of renewal of crystalline lattice singularity node. Direct observation of this oscillation at the tip of the spike is rather problematic because of the mutual superimposition of the electrochemical point-contact switchover effect [4] and the shell effect, that is the effect of layer-by-layer dissolution and deposition of metallic phase, which in an electric field is accompanied by a coherent displacement of some atoms out of their lattice sites and back [4, 12].

Of course, the effective exposure time, that is the forward conductivity interruption time, depends mainly on the current and conductor size. If the conductor diameter is comparable with that of an atom, which is the case in a point contact [13], and the current flowing through the conductor is microamperes or tens of microamperes, then this time interval is no more than one second in most cases [4]. Investigation of the current states of such systems made it possible to find some characteristic nonlinearities in point-contact structures [5]. 


\section{Conclusions}

We propose a phenomenological approach to formalize elongated element as an electrochemical system in which electrode reactions are localized (realized) on the surface of an elongated first-class conductor with its outline dimensions ratio $\left(d / l_{e l}\right) \rightarrow 0$, where $d$ is a linear size characterizing its cross section (diameter), $l_{e l}$ is the length of the conductor in contact with a second-class conductor. This architecture of electrochemical system is used to develop ultrasensitive sensor devices with broad functionality, including those with the purpose of identifying the metabolic profile of a patient in medical practice $[7,14]$. A comprehensive adaptation and further development of the ideas discussed in the paper can greatly contribute to the creation of modern nanotechnologies, improvement of synthesis of low-dimensional structures, and development of a new generation of devices.

\section{References}

1. T.G.Beynik, N.A.Matveevskaya, M.V.Dobrotvorskaya et al., Functional Materials, 24, 021 (2017).

2. V.A.Shkuropatenko, Functional Materials, 23, 092 (2016).
3. A.A.Druzhinin, I.I.Maryamova, O.P.Kutrakov, Functional Materials, 23, 206 (2016).

4. A.P.Pospelov, A.I.Pilipenko, G.V.Kamarchuk et al., J.Phys. Chem. C, 119, 632 (2015).

5. G.V.Kamarchuk, A.P.Pospelov, A.V.Savitsky et al., Low Temp. Phys., 40, 937 (2014).

6. A.P.Pospelov, G.V.Kamarchuk, Yu.L.Alexandrov et al., in: Spectroscopy of Emerging Materials, E.C.Faulques, D.L.Perry, A.V.Yeremenko, Eds., Kluwer Academic Publishers, NATO Science Series: Boston/Dordrecht/London (2004).

7. G.V.Kamarchuk, A.P.Pospelov, L.V.Kamarchuk et al., in: Nanobiophysics: Fundamentals and Applications, V.A.Karachevtsev, Eds., Pan Stanford Publishing Pte. Ltd. (2015).

8. R.S.Tjurin, Yu.S.Lyalikov, S.I.Zhdanov, Uspekhi Khimii, No.12, 2272 (1972).

9. B.B.Damaskin, O.A.Petriy, G.A.Tsirlina, Electrochemistry, Kolos, Moscow (2006) [in Russian].

10. A.I.Pilipenko, A.P.Pospelov, G.V.Kamarchuk et al., Func. Mater., 18, 324 (2011).

11. M.Ved, M.Glushkova, N.Sakhnenko, Functional Materials, 20, 87 (2013)

12. A.I.Yanson, I.K.Yanson, J.M.van Ruitenbeek, Nature, 400, 144 (1999).

13. Yu.G.Naidyuk, I.K.Yanson, Point-contact Spectroscopy, Springer, New York (2005).

14. I.Kushch, N.Korenev, L.Kamarchuk et al., $J$. Breath Res., 9, 047111 (2015). 